\title{
GDNF Is Predominantly Expressed in the PV + Neostriatal Interneuronal Ensemble in Normal Mouse and after Injury of the Nigrostriatal Pathway
}

\author{
María Hidalgo-Figueroa, ${ }^{\star}$ Sonia Bonilla, ${ }^{\star}$ Francisco Gutiérrez, Alberto Pascual, and José López-Barneo \\ Instituto de Biomedicina de Sevilla, Hospital Universitario Virgen del Rocío/CSIC/Universidad de Sevilla, and Centro de Investigación Biomédica en Red \\ sobre Enfermedades Neurodegenerativas (CIBERNED), 41013 Sevilla, Spain
}

Glial cell line-derived neurotrophic factor (GDNF) is absolutely required for survival of dopaminergic (DA) nigrostriatal neurons and protect them from toxic insults. Hence, it is a promising, albeit experimental, therapy for Parkinson's disease (PD). However, the source of striatal GDNF is not well known. GDNF seems to be normally synthesized in neurons, but numerous reports suggest GDNF production in glial cells, particularly in the injured brain. We have studied in detail striatal GDNF production in normal mouse and after damage of DA neurons with MPTP. Striatal GDNF mRNA was present in neonates but markedly increased during the first 2-3 postnatal weeks. Cellular identification of GDNF by unequivocal histochemical methods demonstrated that in normal or injured adult animals GDNF is expressed by striatal neurons and is not synthesized in significant amounts by astrocytes or microglial cells. GDNF mRNA expression was not higher in reactive astrocytes than in normal ones. Approximately $95 \%$ of identified neostriatal GDNF-expressing cells in normal and injured animals are parvalbumin-positive $(\mathrm{PV}+$ ) interneurons, which only represent $\sim 0.7 \%$ of all striatal neurons. The remaining $5 \%$ of GDNF + cells are cholinergic and somatostatin + interneurons. Surprisingly, medium spiny projection neurons (MSNs), the vast majority of striatal neurons that receive a strong DA innervation, do not express GDNF. PV + interneurons constitute an oscillatory functional ensemble of electrically connected cells that control MSNs' firing. Production of GDNF in the PV + neurons might be advantageous to supply synchronous activity-dependent release of GDNF in broad areas of the striatum. Stimulation of the GDNF-producing striatal PV+ ensemble in PD patients could have therapeutic effects.

\section{Introduction}

The glial cell line-derived neurotrophic factor (GDNF) is a potent dopaminotrophic agent that promotes survival, differentiation, and phenotype of neurons. GDNF protects dopaminergic nigrostriatal neurons from neurotoxins in rodents and primates, and induces fiber outgrowth when administered into the brain parenchyma (Tomac et al., 1995; Gash et al., 1996; Kordower et al., 2000). GDNF has also a neuroprotective effect on noradrenergic neurons of the rodent locus ceruleus (Arenas et al., 1995; Pascual

Received May 31, 2011; revised Nov. 10, 2011; accepted Nov. 17, 2011.

Author contributions:A.P. and J.L.-B. designed research;M.H.-F., S.B.,F.G., and A.P. performed research;M.H.-F., S.B., A.P., and J.L.-B. analyzed data; S.B., A.P., and J.L.-B. wrote the paper.

The work was funded by the Marcelino Botín Foundation, the Spanish Ministry of Science and Education, the Spanish Ministry of Health (TERCEL), and the Andalusian Government. CIBERNED is funded by the Instituto de Salud Carlos III. Support from the Spanish Ministry of Science and Education for S.B. ("Juan de la Cierva" postdoctoral contract) and M.H.-F. ("FPI" predoctoral fellowship) is also acknowledged. The GDNF-EGFP mouse was obtained from the Gene Expression Nervous System Atlas (GENSAT) Project, NINDS Contracts N01NS02331 and HHSN271200723701C to The Rockefeller University (New York, NY). We thank L. Puelles for his help in the identification of the structures in neonatal brain mouse; and M. J. Castro, R. Gómez, J. de la Torre, and J. Diaz for advice and technical assistance in some experiments.

${ }^{*}$ M.H.-F. and S.B. contributed equally to this work.

Correspondence should be addressed to either Dr. José López-Barneo or Dr. Alberto Pascual, Instituto de Biomedicina de Sevilla, Campus Hospital Universitario Virgen del Rocío, Edificio IBiS, Avenida Manuel Siurot s/n, E-41013 Sevilla, Spain. E-mail: Ibarneo@us.es or apascual-ibis@us.es.

S. Bonilla's present address: Universidad Europea de Madrid, Facultad de Ciencias Biomédicas, Departamento Ciencias Biomédicas Básicas, C/ Tajo, s/n, Villaviciosa de Odón, 28670 Madrid, Spain.

DOI:10.1523/JNEUROSCI.2693-11.2012

Copyright $\odot 2012$ the authors $\quad 0270-6474 / 12 / 320864-09 \$ 15.00 / 0$ et al., 2008). Based on these data, stimulation of endogenous GDNF production and/or exogenous GDNF administration are considered promising therapeutic strategies for Parkinson's disease (PD) (Kirik et al., 2004; Pascual et al., 2008). Indeed, the clinical effectiveness of intrastriatal infusion of recombinant GDNF has been evaluated in open (Gill et al., 2003) and doubleblind (Lang et al., 2006) clinical trials. Intrastriatal transplantation of GDNF-producing cells has also been tested in parkinsonian animals (Akerud et al., 2001; Toledo-Aral et al., 2003) and humans (Arjona et al., 2003; Mínguez-Castellanos et al., 2007).

Clinical applicability of GDNF, still in an experimental stage, will surely benefit from refinement of the method of delivery in parallel with advances in the knowledge of GDNF function in the normal and injured brain (Check, 2007; Vastag, 2010). In this regard, the recent demonstration that adult nigrostriatal dopaminergic neuron survival is absolutely dependent on striatal GDNF production should stimulate future therapeutic developments in the field (Ibáñez, 2008; Pascual et al., 2008). However, the actual source of striatal GDNF is, surprisingly, not known in detail. GDNF is present in several parts of the brain (mainly striatum, thalamus, and septum) and is normally expressed in neurons (Pochon et al., 1997; Trupp et al., 1997), but the nature of striatal neurons responsible for GDNF synthesis is not fully characterized (Bizon et al., 1999). Moreover, GDNF mRNA is detected in cultured astrocytes and microglia, but whether the trophic factor is produced in relevant amounts in vivo by these cell types has not 
Table 1. GDNF expression in neonatal (P0) and adult (P55) mouse brain

\begin{tabular}{lll}
\hline & Postnatal day & \\
\cline { 2 - 3 } Structure & Neonatal (P0) & Adult (P55) \\
\hline Olfactory bulb & + & + \\
Septum & ++ & +++ \\
Striatum & + & +++ \\
Accumbens nucleus, core & +++ & +++ \\
Accumbens nucleus, shell & - & +++ \\
Striatal-pallidal border & +++ & ++ \\
Thalamus & - & +++ \\
Hypothalamus & ++ & + \\
Substantia nigra & - & ++ \\
Subcommissural organ & - & + \\
Interpeduncular nucleus & +++ & ++ \\
Retrorubral field & ++ & - \\
Oculomotor nucleus & +++ & + \\
Motor trigeminal nucleus & +++ & + \\
Locus ceruleus & + &
\end{tabular}

The study is based on seven brains from GDNF-LacZ mice analyzed per age and structure. - , No X-gal-positive cell found; +, 1-10 GDNF-positive cells/analyzed structure; + +, 10-50 GDNF-positive cells/analyzed structure; ,$+++>50$ GDNF-positive cells/analyzed structure.

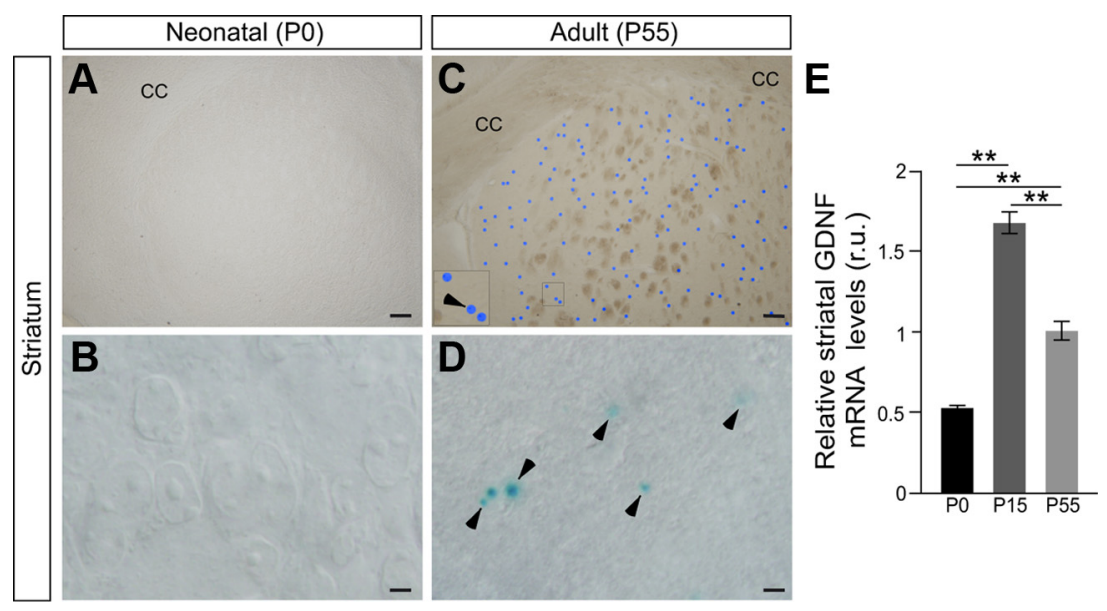

Figure 1. GDNF expression in neostriatum of neonatal and adult mice. $\boldsymbol{A}-\boldsymbol{D}$, GDNF promoter activity estimated by in situ $\beta$-galactosidase enzymatic detection from GDNF-LaCZ mouse brain slices. Blue X-gal precipitate is indicated by arrows. Coronal sections through the neonatal $(\mathrm{P0})(\boldsymbol{A}, \boldsymbol{B})$ and adult $(\mathrm{P} 55)(\boldsymbol{C}, \boldsymbol{D})$ striatum are shown at low $(\boldsymbol{A}, \boldsymbol{C})$ and high $(\boldsymbol{B}, \boldsymbol{D})$ magnification. Scale bars: $\boldsymbol{A}, \boldsymbol{C}, 100 \mu \mathrm{m} ; \boldsymbol{B}, \boldsymbol{D}, 20 \mu \mathrm{m}$. To make visible GDNF expression at low magnification $(\boldsymbol{C})$ a blue dot was drawn over each X-gal-positive cell (see inset). $\boldsymbol{E}$, Relative striatal GDNFmRNA levels estimated by qRT-PCR in neonatal (P0, black bar), juvenile (P15, dark gray bar), and adult (P55, light gray bar) mice. Data (relative to P55) are represented as mean \pm SEM ( $n=8$ for each age group). $\left.{ }^{* *} p<0.01\right)$.

been precisely evaluated (Saavedra et al., 2008). It has been reported that GDNF expression increases under brain injury due to recruitment of GDNF-synthesizing glial cells (astrocytes and microglia), which may eventually become the predominant source of the trophic agent (Hughes et al., 1999; Bresjanac and Antauer, 2000). Nonetheless, this concept is under debate and the actual role of reactive glia in GDNF production in vivo is unsettled (Saavedra et al., 2008).

The objective of this work was to investigate brain GDNF expression in mice, with special emphasis in the identification of the striatal cell (neuron or glia) population producing GDNF. We have studied several genetically modified mouse models to precisely identify the sites of GDNF synthesis. These mice were used in combination with MPTP-treated animals to evaluate in vivo GDNF production by reactive glia. Our data show an unexpected pattern of striatal GDNF expression, linked to the organization and function of the GABAergic synchronous interneuron ensemble. The findings suggest that stimulation of endogenous GDNF-secreting cells could be a feasible methodology of potential clinical relevance.

\section{Materials and Methods}

Mice $(\mathrm{C} 57 \mathrm{BL} / 6 \mathrm{~N}$ strain) were housed under temperature-controlled conditions $\left(22^{\circ} \mathrm{C}\right)$ in a $12 \mathrm{~h}$ light/dark cycle with access ad libitum to food and water. All experiments were performed according to institutional guidelines approved by the ethics committee of the Hospital Universitario Virgen del Rocio and the European Community (Council Directive 86/609/EEC). Heterozygous GDNF-LacZ mice of either sex and outcrossed to C57BL/6N background for $>10$ generations (Sánchez et al., 1996) were used for analysis of the pattern of GDNF expression in neonates (P0; i.e, up to $24 \mathrm{~h}$ after birth), and at P8, P17, and adulthood (2 months old). GDNF promoter activity was estimated by $\beta$-galactosidase enzymatic detection in brains from heterozygous GDNF-LacZ mice (Sánchez et al., 1996; Villadiego et al., 2005). Transgenic GDNF-EGFP mice of either sex were obtained from GENSAT on a mixed background (Gong et al., 2003). Animals were killed either by administration of chloral hydrate anesthesia $(490 \mathrm{mg} / \mathrm{kg}$ ) (adult mice) or by decapitation (neonatal animals).

Histological analyses. Mouse brain was removed from anesthetized animals and immediately fixed overnight ( $15 \mathrm{~h}$; adult mice) or $4 \mathrm{~h}$ (neonatal mice) at $4^{\circ} \mathrm{C}$ with $4 \%$ paraformaldehyde in PBS. Brains included in gelatin were cut in $50-\mu \mathrm{m}$-thick coronal sections using a vibratome (Leica). For the histological detection of GDNF expression, we used heterozygous GDNF-LacZ mice (Sánchez et al., 1996) and the 5-bromo-4-chloro-3-indolyl- $\beta$-Dgalactopyranoside (X-gal)-staining, or GDNFEGFP, mice (Gong et al., 2003) and immunohistochemistry for GFP. In either case, a wild-type animal was used as a negative control in all the experiments. For colocalization studies, immunohistochemistry was performed with the appropriate antibody after X-gal staining or GFP immunohistochemistry. The Envision+ kit (Dako) was used for chromatic immunohistochemistry according to the recommended manufacturer's protocol. Primary antibodies used were as follows: antiNeuN (1:200; Millipore Bioscience Research Reagents); anti-choline acetyltransferase (ChAT) (1:1000; Millipore Bioscience Research Reagents); anti-SS (1:800; Millipore); anti-GFP (monoclonal, 1:100; Roche); antiIBA1 (1:500; Wako); anti-tyrosine hydroxylase (TH) (1:5000; Novus Biologicals); anti-PV28 (1:6000; Swant); anti-glial fibrillary acid protein (1:500; Dako); anti-GFP (polyclonal, 1:1000; Invitrogen); antiDARPP32 (1:200, Millipore; and 1:50, Santa Cruz Biotechnology); anticalbindin (CB) (1:10,000: Swant); and anti-CR (1:8000; Swant). For GFP detection in colocalization studies, we used either mouse (monoclonal) or rabbit (polyclonal) anti-GFP antibodies. In general, the latter provided a stronger signal. Secondary antibodies anti-rabbit or anti-mouse were added in a second step and the reaction was developed with 3,3diaminobenzidine (Dako). For the immunofluorescent studies, we used secondary antibodies anti-mouse IgG or anti-rabbit conjugated with Alexa Fluor 488 or Alexa Fluor 568 (1:800; Invitrogen).

Stereological cell counts. Quantification of GDNF expression in brains of MPTP-treated and control heterozygous GDNF-LacZ mice was done by counting the total number of cells containing $\mathrm{X}$-gal dots. We counted parvalbumin (PV)-, somatostatin (SS)-, and ChATimmunopositive neurons in $50-\mu \mathrm{m}$-thick coronal sections with a vibratome using the C.A.S.T. (Computer Assisted Stereological Toolbox) system (Olympus). Cells positive for both markers (immunohistochemistry and X-gal) were estimated in the caudate-putamen nucleus following Franklin and Paxinos (2008), using 205-273 ran- 
dom 14,260 $\mu \mathrm{m}^{2}$ dissectors. Values are given as mean \pm SEM and relative to the total proportion of each cell type in the striatum (Tepper and Bolam, 2004).

Acute MPTP treatment. Heterozygous, 2-month-old, wild-type GDNF-LacZ or GFAPEGFP mice were rendered parkinsonian by a single subcutaneous administration $(40 \mathrm{mg} /$ $\mathrm{kg}$ ) of MPTP (Sigma). Mice were killed 7, 14, or $21 \mathrm{~d}$ after the lesion, and their brains were processed for immunohistochemistry, cell sorting, or real-time PCR analysis.

Quantitative real-time PCR. Total striatal levels of GDNF mRNA were determined by quantitative real-time PCR (qRT-PCR) in controls (P0, P15, and adult mice) and MPTPinjured mice (7, 14, and $21 \mathrm{~d}$ after lesion). Striatal RNA was extracted using $300 \mu \mathrm{l}$ of TRIzol reagent (Invitrogen) in a homogenizer (Omni TH). RNA samples $(0.5 \mu \mathrm{g})$ were treated with RNase-free DNase (GE Healthcare) and copied to cDNA using SuperScriptII reverse transcriptase (Invitrogen) in a final volume of $20 \mu \mathrm{l}$. Real-time PCR was performed in an Applied Biosystems Prism 7500 Sequence Detection System using TaqMan Gene Expression Master Mix (Applied Biosystems). In the case of mice with MPTP treatment, Actb and Gapdh RNA levels were estimated to normalize for RNA input amounts. A Taqman probe for hydroxymethylbilane synthase (HMBS) gene was used to normalize RNA levels in P0, P15, and adult mice. This gene has been shown to be a bona fide unvaried transcript for quantitative PCR studies of brain genes with low expression levels (Sieber et al., 2010). Two different TaqMan probes were used for estimation of GDNF mRNA levels (exon 1-2 and exon 2-3), and the values obtained were pooled together. To normalize mRNA levels in treated/aged mice to control samples, we calculated an average cycle threshold of the control samples and processed all the samples in the experiment relative to this average cycle threshold. Primers and Taqman sequences are available upon request.

Isolation of GFAP+ striatal cells. Briefly, we dissected the striatum from the brain of GFAPEGFP mice (Zhuo et al., 1997) without lesion and 7, 14, or $21 \mathrm{~d}$ after MPTP administration. The dispersed striatal cells were resuspended in medium containing (for $50 \mathrm{ml}$ ): $44 \mathrm{ml} \mathrm{L} 15 \mathrm{me}-$

dium (Invitrogen), $0.5 \mathrm{ml}$ of penicillin/streptomycin (Cambrex), $0.1 \mathrm{~g}$ of BSA (Sigma), $0.05 \mathrm{ml}$ of HEPES (Invitrogen), and $5 \mathrm{ml}$ of distilled and deionized water. Dead cells $(7-\mathrm{AAD}+)$ were eliminated from sorts and analyses. GFP-positive and -negative striatal subpopulations were isolated in a MoFlo three-laser flow cytometer (Dako and Cytomation) and processed for qRT-PCR analysis.

Statistics. Data are presented as the mean \pm SEM and were analyzed with one-way ANOVA followed by Tukey's test. A $p$ value $<0.05$ was considered statistically significant.

\section{Results}

\section{Postnatal changes of GDNF expression in mouse brain}

We evaluated the level of GDNF expression in neonatal (P0) and adult (P55) animals using a semiquantitative methodology, as determined by the number of X-gal-positive deposits in different brain areas of the GDNF-LacZ mouse. The activity of the GDNF promoter was estimated using $\beta$-galactosidase as reporter (Sán-
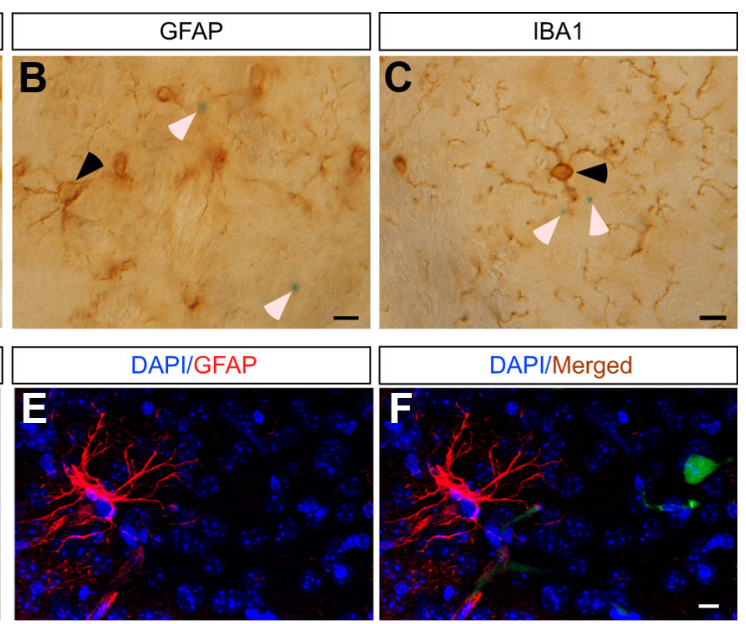

gelective neuronal GDNF expression in adult mouse striatum. $\mathbf{A}-\mathbf{C}$, Striatal coronal sections from GDNF-LaCZ mouse GDNF expression (X-gal staining, blue dots indicated by white arrowheads) and neurons $(\boldsymbol{A}, \mathrm{NeuN}+)$, astrocytes ( $\boldsymbol{B}_{\text {, }}$ GDF-EGFP mouse. GDNF expression is revealed with an antibody against GFP ( $\boldsymbol{D}$, green), and astrocytes are detected by GFAP

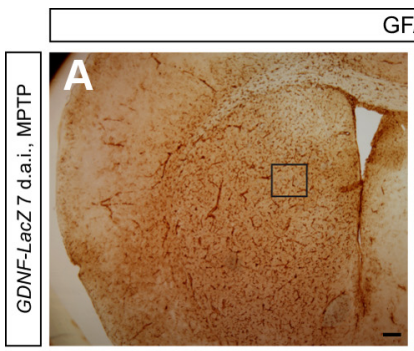

GFAP
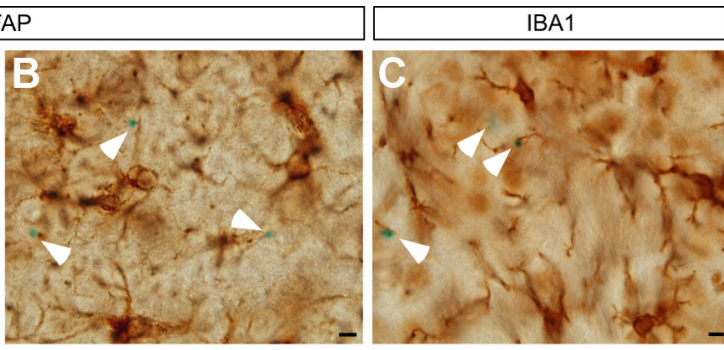
the squares in $\boldsymbol{A}$ and $\boldsymbol{D}$ are shown at higher magnification to demonstrate that the $X$-gal + cells (blue dots indicated by arrowheads) are not GFAP + astrocytes. $\boldsymbol{C}, \boldsymbol{F}$, Striatal IBA1-positive cells do not express GDNF (X-gal staining, blue dots indicated by arrowheads) in MPTP-lesioned (7 and 21 d.a.i.) animals. LV, Lateral ventricle. Scale bars: $\boldsymbol{A}, \boldsymbol{D}, 200 \mu \mathrm{m} ; \boldsymbol{B}, \boldsymbol{C}, \boldsymbol{E}, \boldsymbol{F}, 10 \mu \mathrm{m}$.

chez et al., 1996; Toledo-Aral et al., 2003). In this animal model, previously used by our group to characterize brain regions with strong GDNF mRNA and protein expression (Pascual et al., 2008), $\beta$-galactosidase activity is only found in the sites of GDNF expression in adult brain, as described by using radioactive in situ hybridization (Trupp et al., 1997). We observed a clear change of brain GDNF expression pattern with postnatal maturation (Table 1), thus indicating that in addition to its role in organ and PNS development, GDNF acquires new neurotrophic functions in adult life. Interestingly, GDNF expression was practically absent from neonatal caudate-putamen (Fig. $1 A, B, E$ ), although a significant increase of GDNF mRNA level was observed soon (P15) during postnatal maturation (Fig. 1E). In young adults (P55), cells expressing GDNF were sparsely, but rather uniformly, distributed in the neostriatum (Fig. 1C,D). These observations further demonstrate that GDNF is highly expressed in the adult 

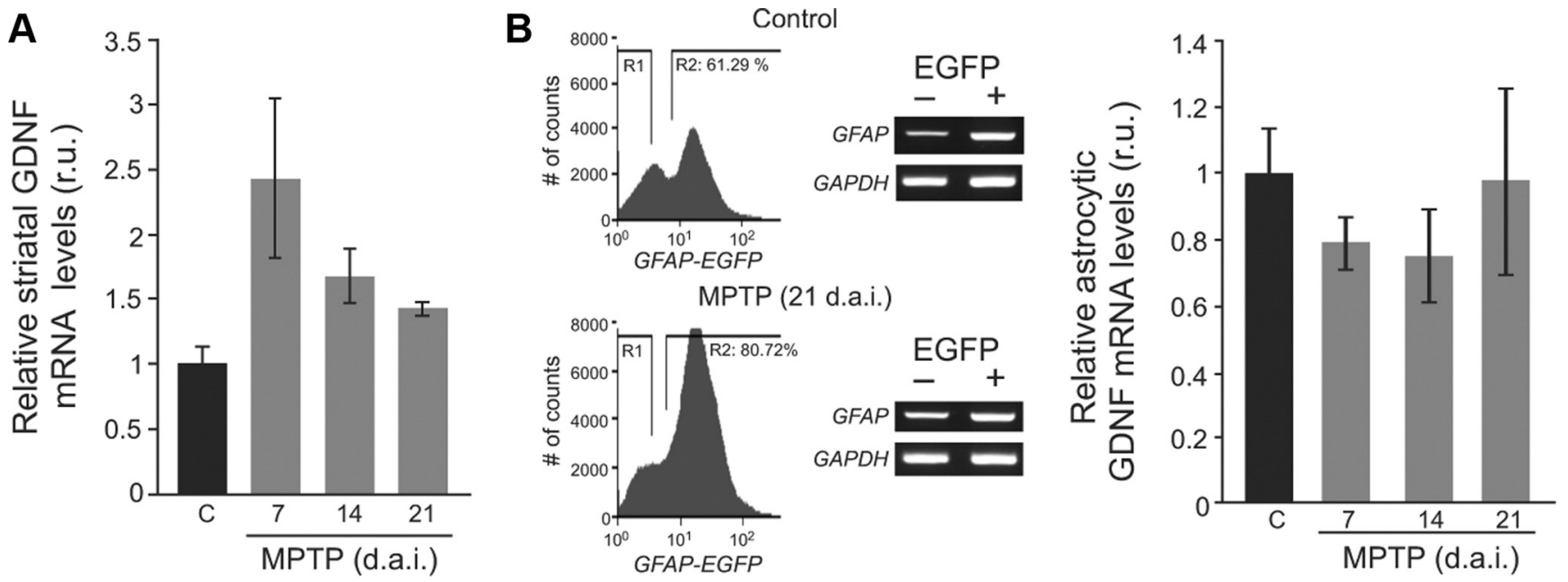

Figure 4. Striatal astrocytic GDNF mRNA expression does not increase after MPTP treatment. $A$, Striatal GDNF mRNA levels estimated by qRT-PCR from total striatum of control (black bar) and MPTP-treated wild-type mice [gray bars; 7,14 , and $21 \mathrm{~d}$ after injury (d.a.i.)]. No significant differences were observed ( $p=0.051$, one-way ANOVA, Tukey's test). $\boldsymbol{B}$, Left, Flow cytometry diagrams showing astrocyte separation by cell sorting from striata of untreated (control) and MPTP-treated (21 d.a.i.) GFAP-EGFP mice. The diagrams show the increase of GFAP-EGFP-positive cells in the striatum after MPTP treatment ( $R 2$ increased from 61.29 to 80.72\%). Center, GFAP mRNA is enriched in the isolated population (EGFP + ) as shown by RT-PCR. The GAPDH gene was used as a loading control. Right, Astrocytic GDNFmRNA levels estimated by qRT-PCR from isolated EGFP + cells of untreated (black bar) and MPTP-treated (gray bars; 7, 14 and 21 d.a.i.) GFAP-EGFP mice. Data [relative units (r.u.) to untreated group] are represented as mean $\pm \mathrm{SEM} ; n=4-8$.

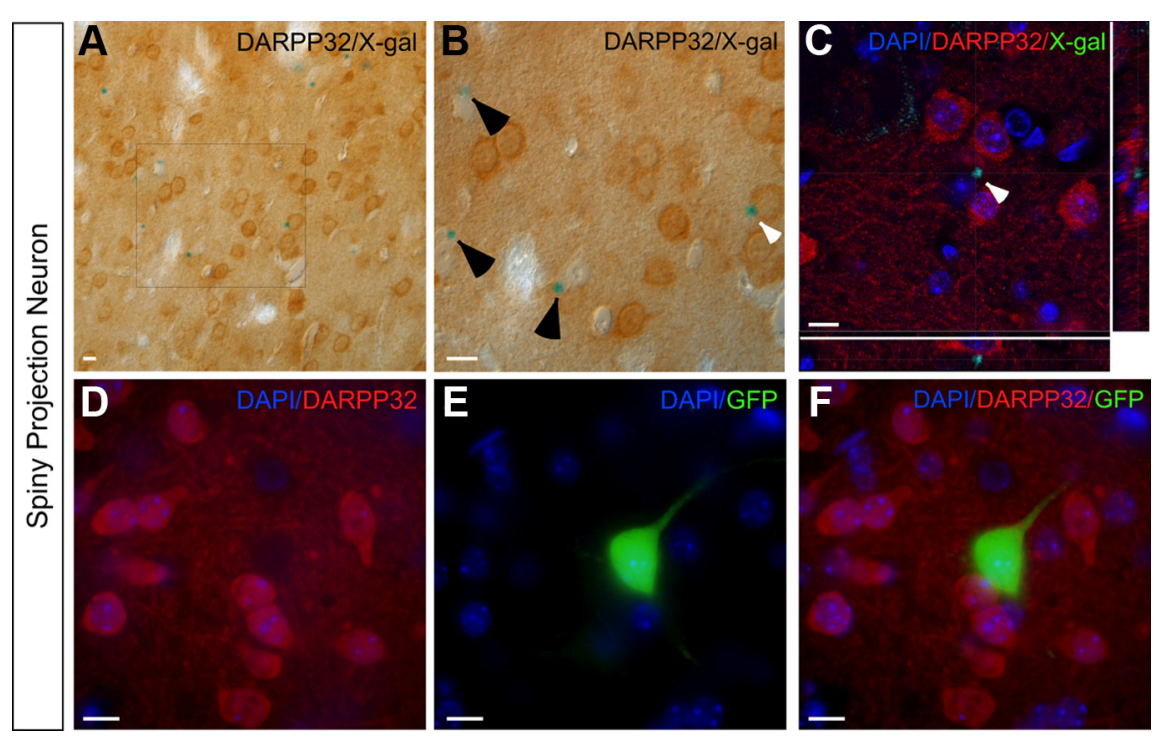

Figure 5. GDNF is not expressed in striatal medium spiny projection neurons. $A$, Striatal coronal sections from GDNF-LacZ mouse showing absence of GDNF expression (X-gal staining, blue dots) in MSNs (DARPP32+). $\boldsymbol{B}$, High magnification of $\boldsymbol{A}$. The white arrowhead points to a blue dot in close apposition to a DARPP32+ neuron. C, Confocal microscopy Z-stacks showing that DARPP32 + MSNs (red) were not X-gal + (green). D-F, Striatal slices from GDNF-EGFP mouse stained with fluorescent antibodies against DARPP32 and GFP (polyclonal). Note the lack of overlapping between the two signals. The planes of $\boldsymbol{C}$ and $\boldsymbol{D}$ were slightly adjusted to make the cells appear into focus.

striatum (Trupp et al., 1997; Bizon et al., 1999; Pascual et al., 2008), and support its neurotrophic function on the dopaminergic nigrostriatal and mesolimbic pathways. During embryonic development, GDNF is not necessary for maintenance of mesencephalic dopaminergic neurons, as these cells are unaffected in GDNF-null animals (Moore et al., 1996; Sánchez et al., 1996). The neurotrophic role of GDNF seems to be acquired later in life, probably once GDNF-producing cells are phenotypically matured in parallel with the postnatal development of the dopaminergic nigrostriatal system (Burke, 2003) (see Identification of GDNFexpressing striatal neurons, below).
GDNF expression in normal and injured adult striatum is confined to neurons and is practically absent from glial cells

To ascertain the cell types expressing GDNF in the normal brain, we stained brain sections from GDNF-LacZ animals with antibodies against neuronal (NeuN), astroglial (GFAP), and microglial (IBA1) markers. Of $>150$ striatal X-gal deposits analyzed (14 sections from three animals), all were found in neurons. In striatal sections stained with antibodies against either GFAP ( 33 sections from 4 animals) or IBA1 (26 sections from 6 animals), we have never detected any X-gal deposit in these types of glial cells. This typical distribution was found in the striatum (Fig. $2 A-C$ ) as well as in other brain areas (thalamus and septum) expressing GDNF (data not shown). The lack of GDNF in normal neostriatal astrocytes was further confirmed using brain sections from GDNF-EGFP mice (Gong et al., 2003) costained with antibodies against GFAP (Fig. 2D-F). These data indicated that in normal brain, GDNF is mostly confined to neurons and is absent from or expressed at low levels in glial cells.

As it has been proposed that GDNF production increases upon brain damage (Hanbury et al., 2003), mainly due to upregulation of the GDNF gene in glial cells (Hughes et al., 1999; Bresjanac and Antauer, 2000; Saavedra et al., 2008), we studied GDNF expression in GDNF-LacZ animals treated with a single MPTP dose to induce partial or complete destruction of dopaminergic nigrostriatal neurons (Mejías et al., 2006). These animals, examined 7-21 d after MPTP injection, exhibited a characteristic strong striatal astroglial reaction (Figure $3 A, D$ ). However, the 


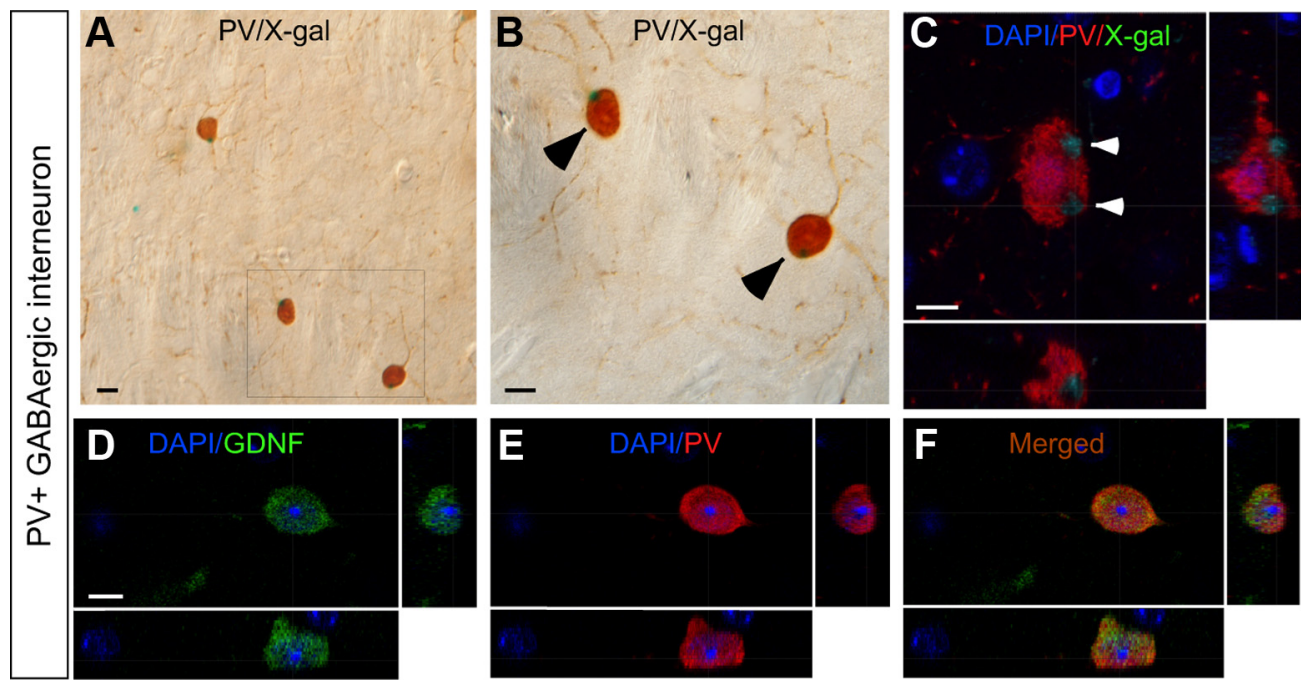

Figure 6. Expression of GDNF in PV + interneurons of adult striatum. $\boldsymbol{A}, \boldsymbol{B}$, Striatal coronal sections from GDNF-LacZ mouse showing GDNF expression (X-gal staining, blue dots) in PV+ interneurons. The square in $\boldsymbol{A}$ is shown at high magnification in $\boldsymbol{B}$. Black arrowheads indicate neurons positive for X-gal and PV. C, Confocal microscopy Z-stacks showing a PV + interneuron (red) that is X-gal + (green). $\boldsymbol{D}-\boldsymbol{F}$, Confocal microscopy Z-stacks of striatal slices from GDNF-EGFP mouse. GDNF-EGFP + neurons ( $\boldsymbol{D}$, green) also express PV marker ( $\boldsymbol{E}$, red). A merged image is shown in $\boldsymbol{F}$. Scale bars, $10 \mu \mathrm{m}$. In $\boldsymbol{D}-\boldsymbol{F}$, we used a mouse (monoclonal) anti-GFP antibody. Highly visible GFP expression was also seen with the GFP polyclonal antibody (data not shown).

pattern of GDNF expression remained unchanged with respect to the one in normal animals. None of the $\mathrm{X}$-gal deposits examined $(n=2946$ in three animals) appeared in either astrocytes $($ GFAP+) (Fig. 3B,E) or microglial (IBA1+) cells (Fig. 3C,F). GDNF mRNA levels were also measured in the striatum removed from MPTP-injured animals by qRT-PCR. In accord with the data obtained with the X-gal technique, lesioned animals showed an increase of GDNF mRNA expression that reached a peak and then declined over the weeks after MPTP injection (Fig. 4A). Three weeks after the lesion, we still observed a nonsignificant 1.5 -fold increase of striatal GDNF mRNA with respect to controls ( $p=0.051$, one-way ANOVA). To further investigate whether brain damage specifically induces GDNF in astrocytes, we performed experiments in MPTP-treated GFAP-EGFP mice (Zhuo et al., 1997) in which striatal astrocytes (GFAP-EGFP+) can be efficiently separated by flow cytometry. As illustrated in Figure $4 B$, MPTP treatment induced a relative $\sim 30 \%$ increase of the GFAP+ cell population (R2 gate) as a consequence of the reactive astrocytosis shown before (Fig. 3). However, in this enriched astrocyte population GDNF mRNA levels were similar to those measured in unlesioned animals (Fig. 4B). Altogether, these findings strongly suggest that striatal GDNF production increases moderately in response to damage of the dopaminergic nigrostriatal neurons. However, glial cells, particularly astrocytes whose number is strongly increased in lesioned animals, do not seem to be a significant source of GDNF. Therefore, the data support the view that striatal neurons, and not glial cells, are the predominant sites of GDNF production in normal and injured animals.

\section{Identification of GDNF-expressing striatal neurons}

Medium spiny projecting neurons (MSNs) represent $90-95 \%$ of the rodent striatal neurons, being the remaining cells in a mixed population of interneurons (Tepper and Bolam, 2004). Among these, a small percentage ( $\sim 0.3 \%$ of all striatal neurons) comprises cholinergic interneurons, and the rest are GABAergic interneurons. GABAergic interneurons are further divided into several neurochemically distinct classes. Approximately $0.7 \%$ of all striatal neurons are interneurons that express the calcium binding protein PV (Tepper and Bolam, 2004). The other populations of GABAergic interneurons express $\mathrm{CB}$, calretinin (CR), or SS (Gerfen et al., 1985; Kawaguchi, 1993; Rymar et al., 2004). Using selective markers to identify the various neuronal subtypes indicated above, we analyzed by immunohistochemistry striata of GDNF-LacZ animals. It was surprising that projection neurons (DARPP32+), the most abundant in the striatum that receive a strong innervation from nigrostriatal dopaminergic cells (Tepper et al., 2010), were never seen to contain X-gal aggregates (Fig. $5 A, B)$. Apparent colocalization of X-gal deposits with DARPP32+ cells observed in some cases, was not confirmed by confocal analyses (Fig. $5 B, C$ ). This finding was also supported by analyzing the GDNF-EGFP mouse, in which DARPP32+ cells (examined in nine striatal sections from three animals) never colocalized with $\mathrm{GFP}+$ neurons (Figure $5 D-F$ ).

Among the population of striatal interneurons, X-gal expression was seen in $83 \%$ of PV + GABAergic interneurons. Qualitatively, GDNF expression was demonstrated both in GDNF-LacZ animals (X-gal deposits) (Fig. 6A-C) and in GDNF-EGFP mice, as well as with the two different GFP antibodies used (Fig. 6D-F). Although in smaller proportion (6\% and 3\%, respectively), GDNF expression was also observed in cholinergic interneurons $(\mathrm{ChAT}+)$, a population of large aspiny cells sparsely but evenly distributed throughout striatum (Fig. $7 A, B$ ) as well as in SS+ (Fig. $7 C, D$ ) interneurons. In contrast, GDNF signals were absent in $\mathrm{CB}+$ or $\mathrm{CR}+$ cells (Fig. $7 E, F$ ). The quantitative summary of neostriatal GDNF expression (Fig. $8 \mathrm{~A}$ ) indicates that among the population of identified GDNF+ (X-gal+) cells, $\sim 95 \%$ were $\mathrm{PV}+$. The remaining GDNF-expressing cells were either ChAT+ (3\%) or SS + (4\%). This distribution of GDNF-synthesizing interneurons remained essentially unaltered in striatum from MPTP-treated animals studied $7 \mathrm{~d}$ after injury (Fig. $8 A$ ). Therefore, the data indicate that both in normal conditions and after toxic damage of dopaminergic nigrostriatal neurons in adult mouse, PV+ GABAergic interneurons are the main neostriatal source of the GDNF necessary for maintenance and survival of the nigrostriatal system. Appearance of striatal GDNF (delayed to the initial P10-P15) (Fig. 1) parallels the ontogenic maturation of PV neurons, which starts in the lateral striatum at approxi- 

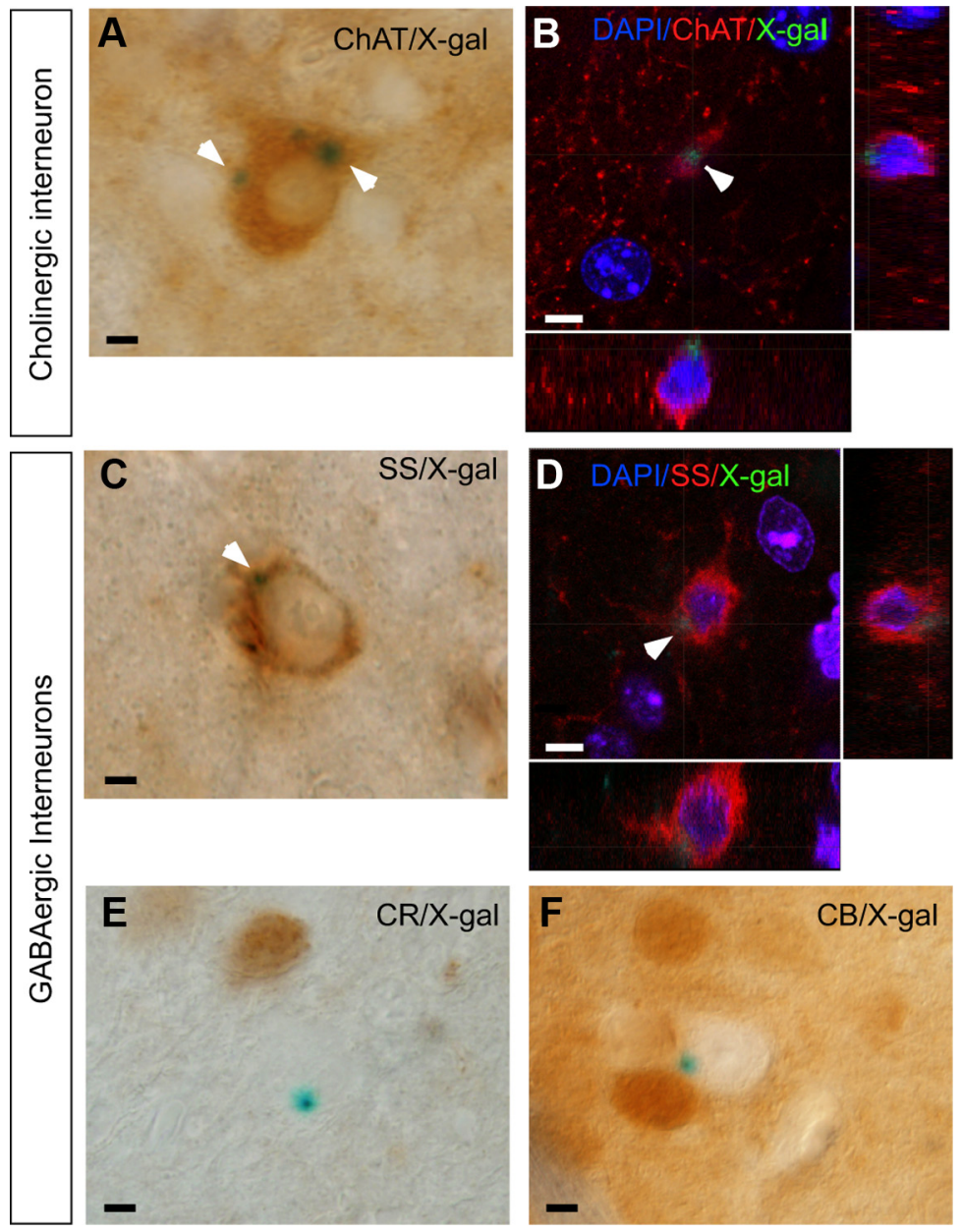

Figure 7. Selective expression of GDNF in ChAT- and SS-positive GABAergic interneurons of adult striatum. $A, B$, Striatal coronal sections from GDNF-LacZ mouse showing GDNF expression (X-gal, blue dots indicated by arrowheads) in ChAT + interneurons. $\boldsymbol{B}$, Confocal microscopy Z-stacks analysis of $\mathrm{ChAT}+$ interneurons. Arrowhead indicates the $\mathrm{X}$-gal precipitate. $\boldsymbol{C}-\boldsymbol{F}$, Striatal coronal sections from GDNF-LacZ mouse showing GDNF expression (X-gal, blue dots) in SS+ $(\boldsymbol{C}, \boldsymbol{D})$ but not in $C R+(\boldsymbol{E})$ or $\mathrm{CB}+(\boldsymbol{F})$ GABAergic interneurons. $\boldsymbol{D}$, Confocal microscopy Z-stacks analysis of SS + interneurons. Arrowheads indicate the X-gal precipitate. Scale bars, $10 \mu \mathrm{m}$

mately P9 in rodents (Schlösser et al., 1999). At this stage (Fig. 8 B, top), GDNF+ neurons are observed in the region where PV expression initiates but overcome in number the PV + cells. This suggests that GDNF synthesis could precede PV expression during interneuron postnatal maturation. Nonetheless, at P18 the number of PV + cells expressing GDNF was similar to that found in adult striatum (Fig. $8 B$, bottom).

\section{Discussion}

In the last decade, GDNF-based therapies have become a promise for the treatment of PD because of the potent trophic effect of this agent on dopaminergic neurons both in vitro (Lin et al., 1993) and in vivo (Tomac et al., 1995). It has also recently been demonstrated that maintenance of the mouse dopaminergic adult nigrostriatal system absolutely depends on neostriatal GDNF production (Pascual et al., 2008), although the source of GDNF is not well known. The design of new GDNF-based therapeutic approaches for $\mathrm{PD}$ would surely benefit from a more precise knowledge of endogenous GDNF function in the normal and injured brain. In this article, we show that GDNF production in mouse striatum develops in early postnatal life and is essentially confined to neurons. We have not detected large amounts of GDNF in glial cells either in normal animals or after damage of the nigrostriatal pathway. In both circumstances, GDNF is absent from the densely innervated striatal MSNs and appears predominantly expressed in PV + GABAergic interneurons.

As other neurotrophic factors, GDNF is normally expressed in low quantities, and its identification by means of standard immunohistochemical methods is hampered by the lack of highly specific antibodies and the low level of expression of the protein (Villadiego et al., 2005; Lonka-Nevalaita et al., 2010). We have overcome this limitation using the GDNFLacZ mouse (Sánchez et al., 1996), which permits unequivocal identification of GDNF-expressing cells. We have shown before in several cell types a close relationship between GDNF promoter activity (as evidenced by X-gal histochemistry) and GDNF synthesis and release (Villadiego et al., 2005). Critical observations on GDNF expression were also confirmed using the GDNF-EGFP mice (Gong et al., 2003) or by qRT-PCR of highly enriched glial cell populations obtained by cell sorting from striata of GFAP-EGFP transgenic animals. Therefore, the main conclusions in this article are based on data obtained with various animal models and complementary methodologies.

In accord with previous reports (Trupp et al., 1997; Pascual et al., 2008), we have further confirmed that the thalamus, septum, nucleus accumbens, and neostriatum show the highest levels of GDNF expression in the adult brain (Table 1). Striatal GDNF is practically absent in neonates, but appears during the second to third postnatal weeks, and its production remains during adulthood (Fig. 1; Table 1). This temporal pattern coincides with postnatal maturation of the nigrostriatal pathway (Antonopoulos et al., 2002; Burke, 2003) and striatal PV + neurons (Schlösser et al., 1999; Chesselet et al., 2007), the ones that show the highest expression of GDNF in adult mouse (see below). Neonatal mesencephalic dopaminergic neurons are normal in the GDNF-null animals (Moore et al., 1996; Sánchez et al., 1996); therefore, it seems that their trophic dependence on this factor develops early after birth in parallel with the maturation and phenotypic specification of dopaminergic nigrostriatal axon terminals and their targets in the striatum. If the same process occurs in humans, one could speculate that subtle developmental alterations produced during this critical time period could eventually result in higher susceptibility to parkinsonism in adulthood.

In normal brain, GDNF was found in significant quantities in striatal neurons rather than in astrocytes or microglia (Fig. 2). In glial cells, GDNF mRNA was amplified by RT-PCR, but the presence of the trophic factor was not observable using either the GDNF-LacZ or the GDNF-EGFP mice (Figs. 2-4). Although there is an abundant literature on the glial expression of GDNF, our findings are in accord with reports suggesting that in central and peripheral neuronal tissues GDNF is normally confined to 
neurons (Pochon et al., 1997; Bizon et al., 1999). In this regard, it is worth mentioning that, similar to the brain, GDNF expression in the adult carotid body, a neuronal crest-derived organ of the peripheral nervous system that contains high levels of this trophic factor (ToledoAral et al., 2003; Pardal et al., 2007), appears in neuron-like glomus cells rather than in the glia-like sustentacular type II cells (Villadiego et al., 2005). As reported before (Hanbury et al., 2003; Saavedra et al., 2008), striatal GDNF expression was upregulated in response to toxic injury of dopaminergic nigrostriatal neurons, but, surprisingly, this appeared to be a consequence of increased GDNF production in neurons rather than in glial cells. Although in MPTP-lesioned animals we observed a clear increase in the number of striatal astrocytes and microglia, evidence of GDNF-LacZ transcriptional activity was seen only in neurons. Furthermore, qRT-PCR analyses of enriched astrocyte populations did not indicate an increase of GDNF expression in reactive glia (studied 7-21 d after lesion) in comparison with controls. These findings clearly contradict a common view, albeit not accepted by all authors, that GDNF production switches from neurons to glial cells in the damaged brain (Saavedra et al., 2008). They could also question, at least in terms of quantitative significance, the putative neuroprotective action of activated glia. Nonetheless, the current study focuses on the MPTP-injured nigrostriatal system, and, therefore, its conclusions cannot be extended to other models in which astrocytic GDNF production has been proposed to have a neuroprotective role (Saavedra et al., 2008).

Our data indicate that the most abundant sources of neostriatal GDNF, either in normal or MPTP-lesioned animals, are GABAergic PV + interneurons that represent $\sim 0.7 \%$ of neostriatal neurons but $\sim 95 \%$ of all GDNF-expressing cells identified in this structure. The remaining GDNF-expressing cells were SS+ and ChAT+ interneurons (Figs. 5-8). MSNs, the most abundant population in the striatum that receive the majority of the nigral dopaminergic afferent fibers were never seen to show X-gal marks or GFP expression indicative of GDNF promoter activity. The fact that MSNs do not seem to contribute to the retrograde neurotrophic support of the nigrostriatal system is an unexpected finding that suggests adaptive specializations within the striatal connectome (Fig. 8C, scheme). PV + interneurons are sparsely distributed over the striatum, and its distribution obeys a ventral-to-dorsal, medial-to-lateral, and caudal-to-rostral gradient of increasing density. This striatal topology coincides with the area innervated by dopaminergic terminals from the substantia nigra (Björklund and Dunnett, 2007). PV+ interneurons receive dopaminergic inputs from the substantia nigra and glutamatergic synapses from thalamus and cortex. Their axons generate powerful proximal inhibitory synapses onto MSNs. As in other parts of the CNS (i.e., cortex or hippocampus), striatal PV + neurons are "fastspiking" cells capable of sustaining high-frequency $(>400 \mathrm{~Hz})$ action potential firing with little afterhyperpolarization or spike frequency adaptation. PV + cells constitute a unique network interconnected by electrical synapses due to dendrodendritic gap junctions, which enable them to fire almost synchronously. Striatal fast-spiking PV cells can resonate at the gamma frequency (Sharott et al., 2009) and are considered to be the major component of a powerful feedforward inhibition that controls spike timing in MSNs, thereby regulating striatal output (Gittis et al., 2010; Tepper et al., 2010; Chuhma et al., 2011). GDNF production in PV+ neurons could be advantageous if the trophic factor is released during periods of activity of the cell functional ensemble (Lonka-Nevalaita et al., 2010), thus interacting with axon 
terminals of practically the entire nigrostriatal pathway. Additional advantages that PV+ interneurons could offer as the source of neurotrophic support for the nigrostriatal pathway result from their presumable high resistance to excitotoxicity, due to the cytosolic content of parvalbumin (a powerful $\mathrm{Ca}^{2+}$ buffering protein) and because repetitive electrical firing depends on $\mathrm{Na}^{+}$rather than on $\mathrm{Ca}^{2+}$ currents (Tepper et al., 2010). Metabolic demands in "fast-spiking" interneurons appear to be coped with through the expression of particularly high levels of oxidative phosphorylation enzymes (Gulyás et al., 2006). In addition to $\mathrm{PV}+$ cells, the other GDNF-producing interneurons might also have a role in the maintenance of projection or local striatal circuits. SS + and ChAT + interneurons, although less numerous than PV + cells, could contribute to nigrostriatal trophic support since they also receive dopaminergic innervation. On the other hand, exogenous GDNF administration seems to protect MSNs in models of Huntington's disease (Alberch et al., 2002). Thus, it could be that in normal conditions GDNF dependent trophic support is provided by cholinergic interneurons, which receive axon collaterals of MSNs (Tepper et al., 2010).

Identification of the ensemble of $\mathrm{PV}+$ interneurons as the main source of striatal GDNF raises numerous questions of potential clinical relevance. Neuroprotection in PD has been attempted so far by continuous administration of exogenous GDNF released locally in the striatum. If endogenous GDNF secretion is actually associated with the synchronized electrical activity of striatal PV cells, it would imply that, in physiologic conditions, the trophic factor is simultaneously released in broad areas of the striatum and with a pulsating or discontinuous time course, circumstances that probably help optimize its neurotrophic actions. In this sense, it is worthy to remark that the number of neostriatal interneurons in primates is higher than in rodents (Tepper and Bolam, 2004). Therefore, stimulation in PD patients of the striatal PV + cell population (e.g., by pharmacological, electric, or magnetic means) to synthesize and release GDNF under controlled conditions could have therapeutic effects.

\section{References}

Akerud P, Canals JM, Snyder EY, Arenas E (2001) Neuroprotection through delivery of glial cell line-derived neurotrophic factor by neural stem cells in a mouse model of Parkinson's disease. J Neurosci 21:8108-8118.

Alberch J, Pérez-Navarro E, Canals JM (2002) Neuroprotection by neurotrophins and GDNF family members in the excitotoxic model of Huntington's disease. Brain Res Bull 57:817-822.

Antonopoulos J, Dori I, Dinopoulos A, Chiotelli M, Parnavelas JG (2002) Postnatal development of the dopaminergic system of the striatum in the rat. Neuroscience 110:245-256.

Arenas E, Trupp M, Akerud P, Ibáñez CF (1995) GDNF prevents degeneration and promotes the phenotype of brain noradrenergic neurons in vivo. Neuron 15:1465-1473.

Arjona V, Mínguez-Castellanos A, Montoro RJ, Ortega A, Escamilla F, Toledo-Aral JJ, Pardal R, Méndez-Ferrer S, Martín JM, Pérez M, Katati MJ, Valencia E, García T, López-Barneo J (2003) Autotransplantation of human carotid body cell aggregates for treatment of Parkinson's disease. Neurosurgery 53:321-328.

Bizon JL, Lauterborn JC, Gall CM (1999) Subpopulations of striatal interneurons can be distinguished on the basis of neurotrophic factor expression. J Comp Neurol 408:283-298.

Björklund A, Dunnett SB (2007) Fifty years of dopamine research. Trends Neurosci 30:185-187.

Bresjanac M, Antauer G (2000) Reactive astrocytes of the quinolinic acidlesioned rat striatum express GFRalphal as well as GDNF in vivo. Exp Neurol 164:53-59.

Burke RE (2003) Postnatal developmental programmed cell death in dopamine neurons. Ann N Y Acad Sci 991:69-79.

Check E (2007) Second chance. Nat Med 13:770-771.
Chesselet MF, Plotkin JL, Wu N, Levine MS (2007) Development of striatal fast-spiking GABAergic interneurons. Prog Brain Res 160:261-272.

Chuhma N, Tanaka KF, Hen R, Rayport S (2011) Functional connectome of the striatal medium spiny neuron. J Neurosci 31:1183-1192.

Frankin KBJ, Paxinos G (2008) The mouse brain in stereotaxic coordinates. San Diego, CA: Academic Press.

Gash DM, Zhang Z, Ovadia A, Cass WA, Yi A, Simmerman L, Russell D, Martin D, Lapchak PA, Collins F, Hoffer BJ, Gerhardt GA (1996) Functional recovery in parkinsonian monkeys treated with GDNF. Nature 380:252-255.

Gerfen CR, Baimbridge KG, Miller JJ (1985) The neostriatal mosaic: compartmental distribution of calcium-binding protein and parvalbumin in the basal ganglia of the rat and monkey. Proc Natl Acad Sci U S A 82:8780-8784.

Gill SS, Patel NK, Hotton GR, O'Sullivan K, McCarter R, Bunnage M, Brooks DJ, Svendsen CN, Heywood P (2003) Direct brain infusion of glial cell line-derived neurotrophic factor in Parkinson disease. Nat Med 9:589-595.

Gittis AH, Nelson AB, Thwin MT, Palop JJ, Kreitzer AC (2010) Distinct roles of GABAergic interneurons in the regulation of striatal output pathways. J Neurosci 30:2223-2234.

Gong S, Zheng C, Doughty ML, Losos K, Didkovsky N, Schambra UB, Nowak NJ, Joyner A, Leblanc G, Hatten ME, Heintz N (2003) A gene expression atlas of the central nervous system based on bacterial artificial chromosomes. Nature 425:917-925.

Gulyás AI, Buzsáki G, Freund TF, Hirase H (2006) Populations of hippocampal inhibitory neurons express different levels of cytochrome c. Eur J Neurosci 23:2581-2594.

Hanbury R, Ling ZD, Wuu J, Kordower JH (2003) GFAP knockout mice have increased levels of GDNF that protect striatal neurons from metabolic and excitotoxic insults. J Comp Neurol 461:307-316.

Hughes PE, Alexi T, Walton M, Williams CE, Dragunow M, Clark RG, Gluckman PD (1999) Activity and injury-dependent expression of inducible transcription factors, growth factors and apoptosis-related genes within the central nervous system. Prog Neurobiol 57:421-450.

Ibáñez CF (2008) Catecholaminergic neuron survival: getting hooked on GDNF. Nat Neurosci 11:735-736.

Kawaguchi Y (1993) Physiological, morphological, and histochemical characterization of three classes of interneurons in rat neostriatum. J Neurosci 13:4908-4923.

Kirik D, Georgievska B, Björklund A (2004) Localized striatal delivery of GDNF as a treatment for Parkinson disease. Nat Neurosci 7:105-110.

Kordower JH, Emborg ME, Bloch J, Ma SY, Chu Y, Leventhal L, McBride J, Chen EY, Palfi S, Roitberg BZ, Brown WD, Holden JE, Pyzalski R, Taylor MD, Carvey P, Ling Z, Trono D, Hantraye P, Déglon N, Aebischer P (2000) Neurodegeneration prevented by lentiviral vector delivery of GDNF in primate models of Parkinson's disease. Science 290:767-773.

Lang AE, Gill S, Patel NK, Lozano A, Nutt JG, Penn R, Brooks DJ, Hotton G, Moro E, Heywood P, Brodsky MA, Burchiel K, Kelly P, Dalvi A, Scott B, Stacy M, Turner D, Wooten VG, Elias WJ, Laws ER, et al. (2006) Randomized controlled trial of intraputamenal glial cell line-derived neurotrophic factor infusion in Parkinson disease. Ann Neurol 59:459-466.

Lin LF, Doherty DH, Lile JD, Bektesh S, Collins F (1993) GDNF: a glial cell line-derived neurotrophic factor for midbrain dopaminergic neurons. Science 260:1130-1132.

Lonka-Nevalaita L, Lume M, Leppänen S, Jokitalo E, Peränen J, Saarma M (2010) Characterization of the intracellular localization, processing, and secretion of two glial cell line-derived neurotrophic factor splice isoforms. J Neurosci 30:11403-11413.

Mejías R, Villadiego J, Pintado CO, Vime PJ, Gao L, Toledo-Aral JJ, Echevarría M, López-Barneo J (2006) Neuroprotection by transgenic expression of glucose-6phosphate dehydrogenase in dopaminergic nigrostriatal neurons of mice. J Neurosci 26:4500-4508.

Mínguez-Castellanos A, Escamilla-Sevilla F, Hotton GR, Toledo-Aral JJ, Ortega-Moreno A, Méndez-Ferrer S, Martín-Linares JM, Katati MJ, Mir P, Villadiego J, Meersmans M, Pérez-García M, Brooks DJ, Arjona V, López-Barneo J (2007) Carotid body autotransplantation in Parkinson disease: a clinical and PET study. J Neurol Neurosurg Psychiatry $78: 825-831$.

Moore MW, Klein RD, Fariñas I, Sauer H, Armanini M, Phillips H, Reichardt LF, Ryan AM, Carver-Moore K, Rosenthal A (1996) Renal and neuronal abnormalities in mice lacking GDNF. Nature 382:76-79. 
Pardal R, Ortega-Sáenz P, Durán R, López-Barneo J (2007) Glia-like Stem Cells Sustain Physiologic Neurogenesis in the Adult Mammalian Carotid Body. Cell 131:364-377.

Pascual A, Hidalgo-Figueroa M, Piruat JI, Pintado CO, Gómez-Díaz R, López-Barneo J (2008) Absolute requirement of GDNF for adult catecholaminergic neuron survival. Nat Neurosci 11:755-761.

Pochon NA, Menoud A, Tseng JL, Zurn AD, Aebischer P (1997) Neuronal GDNF expression in the adult rat nervous system identified by in situ hybridization. Eur J Neurosci 9:463-471.

Rymar VV, Sasseville R, Luk KC, Sadikot AF (2004) Neurogenesis and stereological morphometry of calretinin-immunoreactive GABAergic interneurons of the neostriatum. J Comp Neurol 469:325-339.

Saavedra A, Baltazar G, Duarte EP (2008) Driving GDNF expression: the green and the red traffic lights. Prog Neurobiol 86:186-215.

Sánchez MP, Silos-Santiago I, Frisén J, He B, Lira SA, Barbacid M (1996) Renal agenesis and the absence of enteric neurons in mice lacking GDNF. Nature 382:70-73.

Schlösser B, Klausa G, Prime G, Ten Bruggencate G (1999) Postnatal development of calretinin- and parvalbumin-positive interneurons in the rat neostriatum: an immunohistochemical study. J Comp Neurol 405:185198.

Sharott A, Moll CK, Engler G, Denker M, Grün S, Engel AK (2009) Different subtypes of striatal neurons are selectively modulated by cortical oscillations. J Neurosci 29:4571-4585.

Sieber MW, Guenther M, Kohl M, Witte OW, Claus RA, Frahm C

$(2010)$
Inter-age variability of bona fide unvaried transcripts Normalization of quantitative PCR data in ischemic stroke. Neurobiol Aging 31:654-664.

Tepper JM, Bolam JP (2004) Functional diversity and specificity of neostriatal interneurons. Curr Opin Neurobiol 14:685-692.

Tepper JM, Tecuapetla F, Koós T, Ibáñez-Sandoval O (2010) Heterogeneity and diversity of striatal GABAergic interneurons. Front Neuroanat 4:150.

Toledo-Aral JJ, Méndez-Ferrer S, Pardal R, Echevarría M, López-Barneo J (2003) Trophic restoration of the nigrostriatal dopaminergic pathway in long-term carotid body-grafted parkinsonian rats. J Neurosci 23:141148.

Tomac A, Lindqvist E, Lin LF, Ogren SO, Young D, Hoffer BJ, Olson L (1995) Protection and repair of the nigrostriatal dopaminergic system by GDNF in vivo. Nature 373:335-339.

Trupp M, Belluardo N, Funakoshi H, Ibáñez CF (1997) Complementary and overlapping expression of glial cell line-derived neurotrophic factor (GDNF), c-ret proto-oncogene, and GDNF receptor- $\alpha$ indicates multiple mechanisms of trophic actions in the adult rat CNS. J Neurosci 17:3554-3567.

Vastag B (2010) Biotechnology: crossing the barrier. Nature 466:916-918.

Villadiego J, Méndez-Ferrer S, Valdés-Sánchez T, Silos-Santiago I, Fariñas I, López-Barneo J, Toledo-Aral JJ (2005) Selective glial cell line-derived neurotrophic factor production in adult dopaminergic carotid body cells in situ and after intrastriatal transplantation. J Neurosci 25:4091-4098.

Zhuo L, Sun B, Zhang CL, Fine A, Chiu SY, Messing A (1997) Live astrocytes visualized by green fluorencent protein in transgenic mice. Dev Biol 187: $36-42$. 